\title{
Activity patterns of two syntopic and closely related aerial-hawking bat species during breeding season in Bialowieża Primaeval Forest
}

\author{
I. Ruczyński ${ }^{1}$ P. Zahorowicz ${ }^{1}$ - T. Borowik ${ }^{1} \cdot$ Z. Halat $^{1}$ (D)
}

Received: 7 July 2016 / Accepted: 14 October 2016 / Published online: 24 October 2016

(C) The Author(s) 2016. This article is published with open access at Springerlink.com

\begin{abstract}
Temporal and spatial activity of bats is species specific and shaped by many factors such as energy requirements, climate conditions and food distribution. Pregnancy and lactation are the most energy-demanding periods throughout the female life cycle. During these periods, females have to optimize their activity patterns to maximize foraging success; however, they simultaneously need to take care of their young. In addition, daily and seasonal fluctuations of insect availability strongly affect bat foraging activity. If females, which are under strong energy constraints, belong to closely related species, they may potentially suffer from competition. One of the mechanisms that allows them to avoid competition is temporal and spatial niche partitioning. Noctule and Leisler's bats are closely related forest-dwelling species whose diet is similar and consists mainly of ephemeral insects. The aim of our study was to test if they exhibit similar patterns in relation to the time and duration of their nocturnal activity. In Białowieża Forest, we demonstrated that female nocturnal activity of both noctule and Leisler's bats was shaped mostly by reproductive period and ambient temperature. We did not observe significant differences in the activity patterns of the two noctule species, which suggests that physiological constraints connected with reproduction and environmental conditions affect these species in a similar way and outweigh the competition between species.
\end{abstract}

Communicated by: Karol Zub

Electronic supplementary material The online version of this article (doi:10.1007/s13364-016-0298-5) contains supplementary material, which is available to authorized users.

Z. Hałat

zuzahalat@ibs.bialowieza.pl

1 Mammal Research Institute, Polish Academy of Sciences, Waszkiewicza 1, 17-230 Białowieża, Poland
Keywords Nyctalus noctula $\cdot$ Nyctalus leisleri . Reproduction · Temperature $\cdot$ Niche segregation $\cdot$ Species competition

\section{Introduction}

Bats are the only mammals capable of active flight. The ability to fly allows bats, especially aerial insectivorous species, to cover large distances during the night and decrease risk of predation (Rydell et al. 1996). Although flight ability is beneficial from an evolutionary perspective, it is also a time- and energy-consuming process (Norberg and Rayner 1987; Muijres et al. 2012). Thus, the pattern of daily flight activity should maximize energy intake and minimize the costs of flight and predation risk (Rydell et al. 1996; Speakman and Thomas 2003; Voigt et al. 2010). Temporal and spatial patterns of activity of bats are shaped by many factors, such as temporal and spatial changes in food distribution and the energetic demands of individuals (Neuweiler 2000; Dietz and Kalko 2007; Barclay and Jacobs 2011). Because the diet of bats occurring in the temperate zone contains mainly small flying invertebrates, the activity of which is known to be reliant on ambient temperature (Abdullah 1961; Taylor 1963; Bale et al. 2002), bat activity is also highly dependent on climate and weather conditions (Clare et al. 2011; Frick et al. 2012; Clare et al. 2014). Night activity of females during the breeding season is mainly connected with the necessity for foraging, parental care and roost finding (Neuweiler 2000). The most energydemanding periods for females are pregnancy and lactation (Kunz 1974; Anthony and Kunz 1977; Racey et al. 1987; Barclay 1989). Females need to balance their time out of the roost, which is required to get enough food, with the necessity for regularly returning to feed and warm their young (Rydell 1993; Shiel and Fairley 1999; Vonhof and Betts 2010). 
Females of most bat species deal with the same constraints relating to parental care; however, nocturnal activity patterns in bats are highly species specific. Even in the same climate conditions and reproductive period, females belonging to different species may exhibit different temporal activity patterns. The differences are mainly connected with the various food preferences and hunting strategies (Neuweiler 2000; Dietz et al. 2009). Bats that feed on ephemeral insects that occur in high abundance and unpredictably in space and time usually make only one short bout per night (Racey and Swift 1985; Brigham and Fenton 1991; Shiel et al. 1999; Dechmann et al. 2009). Contrarily, bats whose food is continuously available throughout the whole night feed for a longer time and make more flights (Audet 1990; Chruszcz and Barclay 2003).

The theory of niche differentiation indicates that closely related sympatric species use the environment in a way that allows them to reduce competition for resources. The separation of resource utilization can be based on temporal or spatial partitioning (Kronfeld-Schor and Dayan 2003; Bergeson et al. 2013; Symes et al. 2013). To test if closely related insectivorous bat species exhibit similar patterns, we conducted research on two syntopic, noctule bat species: noctule bats (Nyctalus noctula) and Leisler's bats (Nyctalus leisleri). The diets of both species consist mainly of ephemeral insects and their night activity lasts only a few hours. Majority of noctule bat prey consists of swarm insects, i.e. Trichoptera, Diptera (mostly Chironomidae) and Lepidoptera. In spring and autumn, they also forage on mass emergences of large insects from Hemiptera and Coleoptera (Beck 1995; Gloor et al. 1995; Mackenzie and Oxford 1995). Leisler's bats have similar food preferences and they forage predominantly on smalland medium-sized insects forming swarms. Their diet consists primarily of Lepidoptera, Diptera (mainly Tipulidae), Trichoptera (Beck 1995; Shiel et al. 1998) and Hymenoptera (Kaňuch et al. 2005). These two bat species are dependent on forest as they roost mainly in trees (Bihari 2004; Bogdanowicz and Ruprecht 2004; Gebhard and Bogdanowicz 2004). The noctule bat is widespread across its range and known to be one of the most common forest-dwelling bats in Europe, unlike Leisler's bat, which is rather rare apart from in Spain, southern France, Germany and the Balkans (Horàcek et al. 2000; Dietz et al. 2009). Both species migrate seasonally from the south or southwest to Białowieża Primaeval Forest, which is one of their important breeding sites (Bogdanowicz and Ruprecht 2004; Gebhard and Bogdanowicz 2004; Kaňuch et al. 2004). Aggregations last from May until August (Ruczyński and Bogdanowicz 2005). Breeding colonies usually comprise 20-60 individuals in noctule bats and 20-50 in Leisler's bats (Bogdanowicz and Ruprecht 2004). In the study area, parturitions in both species take place in mid-June and females wean young around late July (Ruczyński 2006b). Although previous surveys provided detailed information on roost utilization
(Ruczyński and Bogdanowicz 2005; Ruczyński et al. 2007; Ruczyński and Bogdanowicz 2008; Ruczyński and Bartoń 2012) and foraging activity during pregnancy and lactation (Kronwitter 1988; Jones 1995; Shiel and Fairley 1999; Shiel et al. 1999; Kaňuch et al. 2005; Kaňuch 2007; Nad'o and Kaňuch 2015) for both species, there was no comparative study of these two species inhabiting the same forest area. Our study aims to compare the patterns of nocturnal activity of the two noctule bats in primaeval forest conditions.

We hypothesized that in both species, the temporal foraging patterns, i.e. the duration and time of nocturnal activity and number of flights, are shaped by the reproductive status of females. To test our hypotheses, we searched the bat roosts and monitored their emergences and nocturnal activity with radiotelemetry. We expected females of two Nyctalus species to (i) increase number of flights per night and their duration after parturitions and hasten the onset of emergence when lactating, as well as (ii) lengthen their nocturnal activity in higher ambient temperatures and (iii) exhibit similar activity patterns.

\section{Study area, methods and material}

\section{Study area}

Our study was conducted in the Białowieża Primaeval Forest (BPF). This large temperate mixed lowland forest covers an area of $1450 \mathrm{~km}^{2}$, partially in Poland $\left(600 \mathrm{~km}^{2}\right)$ and partially in Belarus. BPF in Poland $\left(52^{\circ} 45^{\prime} \mathrm{N}, 23^{\circ} 50^{\prime} \mathrm{E}\right)$ is divided into Białowieża National Park $\left(105 \mathrm{~km}^{2}\right)$ and managed forest. The study area $\left(100 \mathrm{~km}^{2}\right)$ covered well-preserved stands of Białowieża National Park (BNP), as well as parts of the managed forest with old-growth remnants (over 80-100 years). The climate is continental (Olszewski 1986), with the highest average temperature in July $\left(17.8^{\circ} \mathrm{C}\right)$ and lowest in January $\left(-4.7^{\circ} \mathrm{C}\right)$. The daily temperature amplitude is high in spring and summer. During the study period, the night's duration varied from 7:05-9:25 h. The five main forest types in this area are deciduous forest (Quercus robur, Tilia cordata and Carpinus betulus), mixed deciduous forest (Picea abies, $Q$. robur, $T$. cordata and $C$. betulus), black alder bog forest and streamside alder-ash forest (Alnus glutinosa and Fraxinus excelsior), mixed coniferous forest (Pinus sylvestris, P. abies and $Q$. robur) and coniferous forest (P. sylvestris and $P$, abies) (Faliński 1986; Bernadzki et al. 1998). The superabundance of holes in this forest provides shelters for a wide variety of animals; there are 16 secondary cavity nesting bird species inhabiting BPF (Wesołowski 2007). The area is inhabited by 15 species of bats (Ruczyński and Ruczyńska 2008; Rachwald and Ruczyński 2015); all of which use the forest as roosting sites, foraging sites or safe commute routes. 
Table 1 ANOVA table for the top-ranked linear model (LM) assessing the effects of species (Nyctalus noctula and Nyctalus leisleri), reproductive period (pregnancy and lactation) and time of sunset on the time of emergence onset

\begin{tabular}{llrr}
\hline Variable & Mean squared error & $F$ value & $p$ value \\
\hline Time of sunset & 0.003 & 42.06 & $<0.001$ \\
Species & 0.0001 & 1.40 & 0.239 \\
Reproductive period & 0.001 & 14.46 & $<0.001$ \\
\hline
\end{tabular}

\section{Capture}

We caught bats (1998-2002) with mist nets by small forest rivers (Łutownia, Narewka, Hwoźna and Złota) and by a little pond at the edge of the forest (BNP). We identified bats at the species level and assessed their sex, age and reproductive status. Reproductive state was classified as non-pregnant, pregnant or lactating; pregnancy was assessed by palpation of the abdomen, while the indicator for lactation was a hairless area around the nipples. Based on this information the parturition time was estimated. All handling procedures were performed under the permission from the Ministry of Environment of Poland.

\section{Radio tracking}

We attached small transmitters $(0.5 \mathrm{~g}$, Biotrack, Wareham, UK, Titley Electronics Pty. Ltd., Ballina, New South Wales, Australia; $0.7 \mathrm{~g}$, Titley Electronics, and Holohil System, Carp, Ontario, Canada) to the interscapular region of bats with surgical adhesive (Skin-Bond, Smithand Nephew, Largo, Florida). The mass of the applied transmitters never exceeded $5 \%$ of the bats' body mass (Aldridge and Brigham 1988). We radio tracked a total of 26 noctule bats (10 pregnant females, 11 lactating females, 3 juvenile females and 2 juvenile males) and 25 Leisler's bats (10 pregnant females, 12 lactating females, 1 juvenile female and 2 juvenile males). We used $\mathrm{H}$ shaped handmade antennae and two types of receivers (Yupiteru, MVT-700, Javiation, Bradford, West Yorkshire, United Kingdom and Yaesu FT-290R, Vertex Standard, Cypress, California) to locate the position of tagged bats. We searched roost sites from May to August in 1998-2000 and 2002 (Leisler's bat) and in 1999-2002 (noctule bat). Bats were radio tracked each day as long as signals from the transmitters were found; the average tracking period was 6.5 days (range 114 days) for noctule bat and 7.5 days (range 2-13 days) for Leisler's bat.

Observations of radio tracked bats allowed us to estimate the minimum time duration that animals spent in
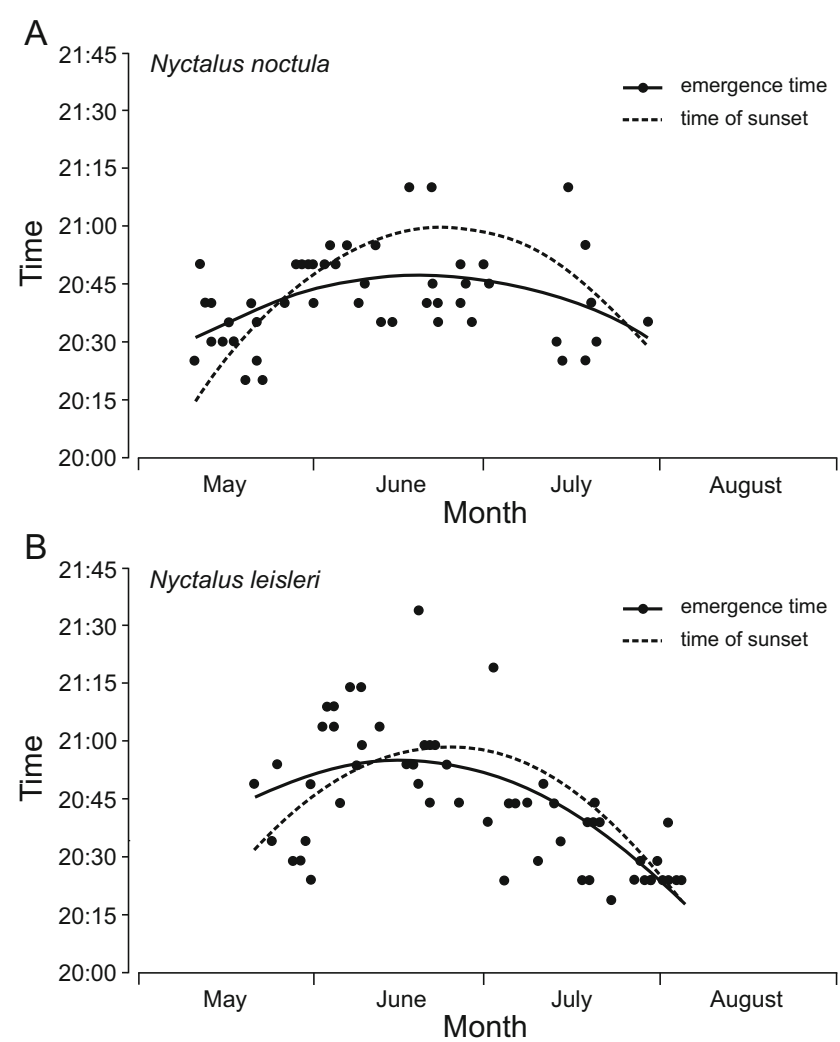

Fig. 1 Variation in the onset of bat emergence over the summer with reference to the time of sunset. The changes in timing of emergence in a noctule bat (1999-2002; $N=48$ ) and b Leisler's bat (1998-2000, 2001; $N=58$ ). Dashed lines denote time of sunset; black lines show polynomial trend line for the onset of bat emergence

their roosts. We checked if bats were in their roost every $10 \mathrm{~min}$, from their evening emergence until sunrise. Only all-night observations were analysed further; we excluded nights with foul weather and nights when bats lost transmitters or changed their roosts. Finally, only 46 of 98 observations (21 noctule bats and 25 Leisler's bats) were analysed.

\section{Emergence observations}

Emergence counts at dusk started 30-40 min before sunset and continued until it was totally dark. Noctule bats were observed from May to August 1999-2002 and Leisler's bats in 1998-2000 and 2002. The time of emergence of the first bat and the duration of all emergences were recorded for 48 evenings for the colonies of noctule bats and 58 evenings for Leisler's bats. The identification of species emerging from each roost was based on the presence of radio-tagged individuals. However, mixed species bat aggregations are also known in BPF (Ruczyński and Ruczyńska 2000). 
Table 2 ANOVA table for the top-ranked linear model (LM) assessing the effects of species (Nyctalus noctula and Nyctalus leisleri), reproductive period (pregnancy and lactation) and temperature on activity duration

\begin{tabular}{lccc}
\hline Variable & Mean squared error & $F$ value & $p$ value \\
\hline Temperature & 70,790 & 13.95 & 0.001 \\
Temperature`2 $^{2}$ & 37,100 & 7.31 & 0.010 \\
Reproductive period & 30,284 & 5.97 & 0.019 \\
Temperature $\times$ reproductive period & 327 & 0.06 & 0.801 \\
Temperature^2 $\times$ reproductive period & 36,828 & 7.26 & 0.010 \\
\hline
\end{tabular}

\section{Statistical analysis}

To verify if species considered reproductive period and ambient temperature affected duration of bat activity and number of bat flights per night, we applied a linear model (LM) and generalized linear model (GLM) for count data (Poisson family), respectively. The global models included the following: (1) the main effects of all explanatory factors (species, reproductive period and ambient temperature), (2) quadratic terms for temperature and (3) two-way interactions between all three explanatory variables. LM was also used to assess the effect of sunset time, species and reproductive period on the time of bat emergence. The global model included the main and interactive effects (two-way interaction) of all variables considered.

For all models, every explanatory variable was standardized to a mean of 0 and a SD of 0.5 by using the standardize function within the "arm" package (Grueber et al. 2011; Gelman and $\mathrm{Su}$ 2015). Then, we applied model ranking based on the Akaike information criterion (AIC) with a second-order correction for small sample size $\left(\mathrm{AIC}_{\mathrm{c}}\right)$ available within the dredge function ("MuMIn" package; (Bartoń 2015)); the results are given in Table S1 (Online Resource 1). The top-ranked, most parsimonious submodels were selected as the single best models. Analyses were performed using R software version 3.2.3 (R Core Team 2015).

\section{Results}

The time of sunset affected emergence onset of both bat species. The time of emergence onset increased with growing time of sunset (LM, $R^{2}=0.36, P<0.001$, Table 1). Over the summer, the daily timing of emergence did not differ between species and in both species, it changed dependently on reproductive period $(P<0.001$, Table 1$)$. Noctule bats started to leave their roosts on average $( \pm \mathrm{SD}) 2.0 \pm 11.5 \mathrm{~min}(N=27)$ after sunset during pregnancy, while in lactation, they emerged on average $10.0 \pm 13.95 \mathrm{~min}(N=21)$ before sunset. In Leisler's bat, the observed onset of emergence during pregnancy was on average $6.0 \pm 13.3 \mathrm{~min}(N=19)$ after sunset and during lactation on average $5.0 \pm 12.5 \mathrm{~min}(N=39)$ before sunset. At the end of July, the observed onset of emergence was later in both species (Fig. 1).

In noctule bats, the average total time spent outside the roost during the night $( \pm \mathrm{SD})$ was $119 \pm 45$ min during pregnancy, increasing to $137 \pm 34$ min after parturition. A similar pattern was observed in Leisler's bats; time out of the roost varied from $132 \pm 93$ min during pregnancy to $190 \pm 91 \mathrm{~min}$ after parturition. Duration of bat activity (both species) was significantly affected by the interactive effect of temperature and reproductive period (LM, $R^{2}=0.463, P<0.05$, Table 2, Fig. 2). As the temperature increased, the length of time that the animals spent out of the roosts almost linearly extended in
Fig. 2 Influence of mean daily ambient temperature on the activity duration of noctule and Leisler's bats in pregnancy and lactation periods. Dotted lines denote $95 \%$ confidence intervals

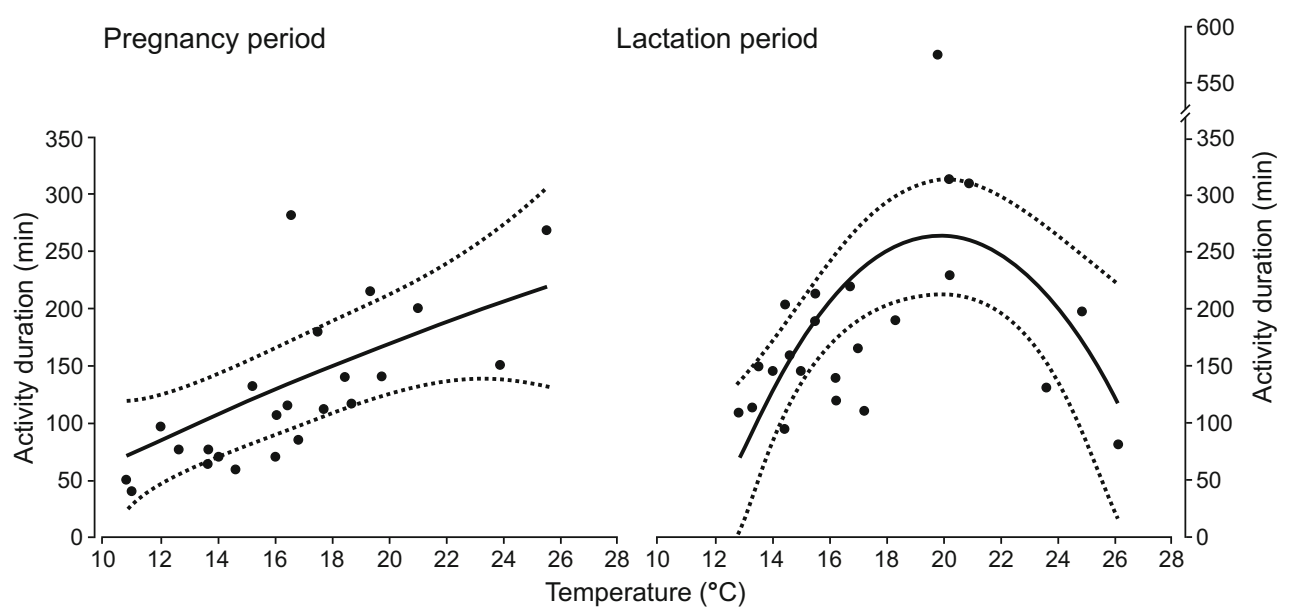


Fig. 3 Variation in the percentage of radio telemetry bearings, when bats were out of the roosts over the night for noctule bat in pregnancy (a) and lactation periods (b) and for Leisler's bat in pregnancy (c) and lactation periods $(\mathbf{d})$

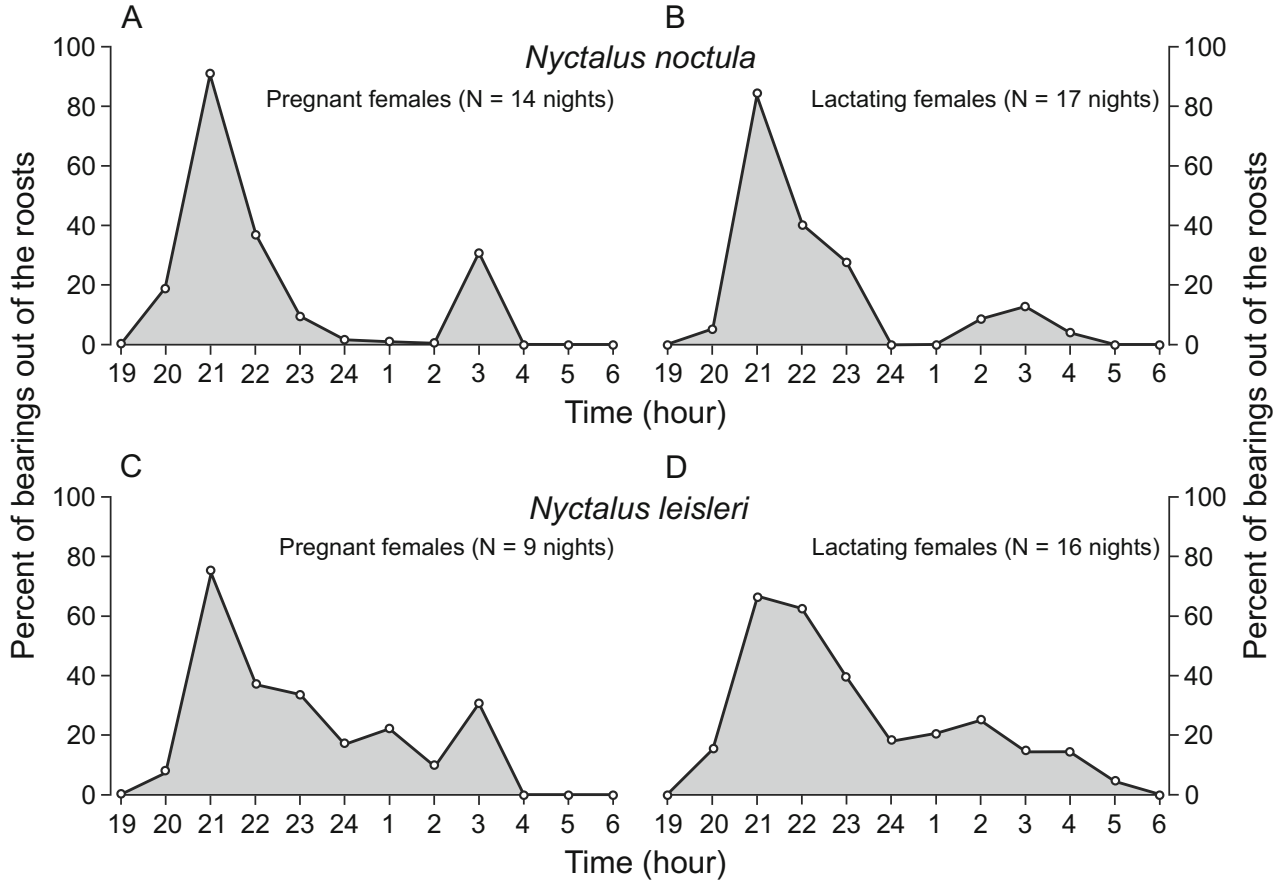

pregnancy period, while during lactation, duration of activity increased at moderate temperatures $\left(13.5-21{ }^{\circ} \mathrm{C}\right)$ and decreased when temperature exceeded $21^{\circ} \mathrm{C}$ (Fig. 2). We did not observe species-related differences in effect of ambient temperature on activity duration.

Both before and after parturitions, two peaks of nocturnal activity were observed in noctule bats, when bats spent significant amount of time away from the home roost. During the first peak of activity ( 9 pm-10 pm), up to $91 \%$ of radio telemetry bearings were out of the roosts, while during the second peak ( 2 am-4 am), $-31 \%$. In Leisler's bat, only one noticeable peak of activity was observed, from $9 \mathrm{pm}$ to $10 \mathrm{pm}$. In subsequent hours, animals spent progressively less time out of their roosts (Fig. 3).

Pregnant noctule bat females performed on average $( \pm \mathrm{SD})$ $1.6 \pm 0.6(N=14)$ flights per night, similarly to Leisler's bats $1.5 \pm 0.8(N=9)$. After parturitions, the number of flights per night increased significantly (GLM, $P<0.05$ ), to $2.0 \pm 1.2$ $(N=7)$ in noctule bat and $3.0 \pm 1.9(N=16)$ in Leisler's bat. The species and ambient temperature did not affect the number of flights per night.

In noctule and Leisler's bat, we did not find any significant correlation between the number of flights and the time spent outside the roost $(R=0.05$ and $R=0.20$, respectively). The first flight was the longest and for noctule bat was on average $99 \mathrm{~min}$ in pregnancy and during lactation $113 \mathrm{~min}$. Subsequent flights were shorter and lasted on average 3 to $17 \mathrm{~min}$. In Leisler's bat, the mean duration of the first flight for females was 77 min during pregnancy and $139 \mathrm{~min}$ after parturitions. The next foraging bouts lasted on average 1 to $43 \mathrm{~min}$.

\section{Discussion}

Our studies demonstrated that female nocturnal activity of two closely related species noctule and Leisler's bats is shaped mostly by reproductive period and ambient temperature. Bats spent more time foraging after parturitions (longer flights and earlier emergences), while the duration of activity also increased with higher temperatures. We did not observe any significant differences in the activity patterns of the two noctule species, which suggests that physiological constraints connected with reproduction and environmental conditions affect these species in a similar way. This may indicate that competition between these species does not have a significant impact on their activity patterns which can suggest that niche segregation is not based on shifting of temporal activity.

Our studies showed that energetic demands connected with reproduction costs are crucial for shaping activity of noctules. Pregnant females emerged later, and their duration of activity was shorter in comparison to lactating females. Possibly, lactating females, due to their higher energetic requirements, start foraging earlier and elongate time of activity, even if potential insect availability during the lactation period is higher (Anthony and Kunz 1977). These observations are comparable to studies conducted on noctule bats and other species of aerial-hawking bats, e.g. Myotis lucifugus and Eptesicus nilsonii (Kunz 1974; Anthony and Kunz 1977; Rydell 1993; Jones 1995; Duverge et al. 2000; Shiel and Fairley 2000). However, some authors suggest that there is no correlation between foraging and reproductive season because insect abundance is higher during lactation (higher mean ambient 
temperatures) and lower female wing loading after parturition, which makes foraging a less energy-consuming process (Kunz 1974; Anthony and Kunz 1977). Females of noctule and Leisler's bats increase the number of flights after parturition which is probably affected by the parental care, i.e. warming up of young and the necessity of feeding them during the night. A higher number of bouts in lactating females was also observed in Indiana bats Myotis sodalis, which during pregnancy never come back to the roost before dawn, while after parturitions $2-4$, flights were recorded (Murray and Kurta 2004). In Leisler's bats, an increasing number of flights was documented by Shiel et al. (1999), where the first bout was always the longest, irrespective of the reproductive period. In our studies, the first flight was also always the longest and its duration was prolonged after parturition.

Insect activity is highly positively correlated with ambient temperature (Abdullah 1961; Taylor 1963; Bale et al. 2002). Low temperature constrains insect activity patterns, so insect density becomes much lower soon after sunset, when temperature decreases (Kunz 1973; Racey and Swift 1985; Rydell et al. 1996; Polakowski et al. 2014). A second peak of insect density starts at the end of the night (Racey and Swift 1985; Rydell et al. 1996). It is known that bat activity is also highly dependent on ambient temperature and insect availability (Racey and Swift 1985; Speakman and Thomas 2003; Wolbert et al. 2014). In view of this, bats should emerge earlier and elongate their night activity to match the periods of the highest density of insects. The relatively cold climate of BPF could explain noctule bats engaging in earlier emergences, even before estimated parturition time; while in other studies, this pattern overlapped with the onset of lactation (Kunz 1974; Jones 1995; Shiel et al. 1999; Duverge et al. 2000). Benefits of reaching the feeding areas before insect abundance depletion have to outweigh the risk of predation (Barclay 1989; Barclay 1991; Shiel and Fairley 1999; Shiel et al. 1999; Frick et al. 2012) and food competition with diurnal birds (Speakman 1991; Speakman 1995). Noctule bats in our studies started their emergences as much as $25 \mathrm{~min}$ before sunset. This is consistent with observations by Polakowski et al. (2014) over the Siemianowka reservoir, where noctule bats started to forage as much as $15 \mathrm{~min}$ before sunset. In both noctule and Leisler's bats, ambient temperature determined also the duration of being out of the roost. Rising ambient temperature (up to $21^{\circ} \mathrm{C}$ ) increased the total time of bat activity - the pattern commonly observed in other bat species (Anthony et al. 1981; Kronwitter 1988; Maier 1992; Catto et al. 1995). In a pregnancy period, the activity duration extended almost linearly with the growing temperature, while during lactation, it decreased after the temperature exceeded $21{ }^{\circ} \mathrm{C}$. A decrease in activity duration in lactating period can result from the fact that lactating tree-roosting females may use torpor more often than pregnant females. Females of Eptesicus fuscus became torpid more frequently after nights with a shorter activity duration (Rintoul and Brigham 2014). Longer and deeper torpor bouts are potentially more profitable for lactating than for pregnant females. The saved energy can be used in milk production (Studier and Ofarrell 1972; Dzal and Brigham 2013). Yet, there are studies reporting opposite relationship, where pregnant females use torpor more often than lactating individuals (e.g. Audet and Fenton 1988; Dietz and Kalko 2006). Interestingly, Bell et al. (1986) showed that time that bats (Macrotus californicus) have to spend foraging is inversely correlated with the roost temperature which is remarkably associated with ambient temperature (Ruczyński 2006a). This phenomenon may be explained by higher water loss in lactating females (Kurta et al. 1990) or by the heat dissipation limit hypothesis, providing that lactating active animals, when facing high temperatures, cannot increase their food intake or milk production, because they are not able to dissipate body heat generated as a by-product of milk production (Król and Speakman 2003).

The lack of prominent differences between the activities of the two studied species can be explained by their similar ecology and the similar physiological and environmental constraints shaping their behaviour. Both species belong to the aerial-hawking bats, feeding mainly on ephemeral insects, whose availability changes over the night (Safi 2008). Moreover, both noctules are strictly tree-dwelling bats in BPF, which occupy similar roosts (Ruczyński and Bogdanowicz 2005). The thermal properties of roosts affect bat thermoregulatory behaviours similarly, so energetic requirements are also probably comparable. The lack of prominent differences in the activity of the bats also indicates that food niche segregation is not based on the shifting of temporal activity. Being active during a time of lower food availability can negatively affect the fecundity of animals. Therefore, mechanisms based on segregation in space, such as those observed among males and females of Daubenton's bats, seem to be more efficient (Senior et al. 2005; Encarnação 2012; Nardone et al. 2015). Bats may also choose different foraging sites in relation to their prey detection strategy and manoeuvrability (Norberg and Rayner 1987; Siemers and Schnitzler 2004). Although both species are opportunistic consumers of flying insects and their flying technique is quite similar - the flight is usually direct and very fast (Jones 1995; Bogdanowicz and Ruprecht 2004; Gebhard and Bogdanowicz 2004; Kaňuch et al. 2005), they slightly differ in selection for habitats to forage. Unlike noctule bats, beside open landscapes, Leisler's bats utilize large woodlands, where they forage predominantly in the forest clearings (Kowalski and Ruprecht 1981; Kronwitter 1988; Rachwald 1992; Sachanowicz and Ciechanowski 2005). However, selection of foraging sites for both species highly depends on study site (Shiel et al. 1998; Shiel and Fairley 1999; Dietz et al. 2009). Based on authors' experience, in BPF, $N$. leisleri hunts predominantly in forest 
stands, while they occurred rarely over the water bodies or in open areas. This may suggest that spatial segregation mechanism of food niche segregation could prevail over temporal one.

In summary, we showed that during pregnancy and lactation, both noctule and Leisler's bats exhibit similar patterns of activity, which are mainly dependant on the development level of young and ambient temperature. Further studies including the relative density of insects in different periods of the breeding season would help to answer the questions about differences in the feeding patterns of these two closely related species in BPF.

Acknowledgments We are grateful to those who helped with fieldwork, particularly C. Duriez, M. Pohlers, A. Baranowski, A. Arasim, S. Barthwood, J. van Beek, M. Blaice, M. Cox, A. Domen, A. Domżalska, A. Dorenda, K. Gmitruk, J. Górniak, T. van Grup, K. Gryka, D. Koncewicz, K. Mazurska, J. Mieczkowska, A. Misiak, I. Ruczyńska, K. Sachanowicz, H. Zalewska, R. Szordykowski, A. Wower, K. Zając, R. Zwolak, T. Zychowicz, the members of the Students' Scientific Club, Academy of Podlasie in Siedlce and Tomasz Diserens for revising the English. We are also grateful to two anonymous referees for the valuable comments. The study was funded by a grant from the Polish State Committee for Scientific Research (3PO4F 00822). Zuzanna Hałat was supported by a grant from the Polish National Science Centre on the basis of decision number DEC-2013/10/E/NZ8/00725.

Open Access This article is distributed under the terms of the Creative Commons Attribution 4.0 International License (http:// creativecommons.org/licenses/by/4.0/), which permits unrestricted use, distribution, and reproduction in any medium, provided you give appropriate credit to the original author(s) and the source, provide a link to the Creative Commons license, and indicate if changes were made.

\section{References}

Abdullah M (1961) Behavioural effects of temperature on insects. Ohio J Sci 61:212-219

Aldridge H, Brigham RM (1988) Load carrying and maneuverability in an insectivorous bat - a test of the 5-percent rule of radio-telemetry. J Mammal 69:379-382. doi:10.2307/1381393

Anthony ELP, Kunz TH (1977) Feeding strategies of little brown bat, Myotis lucifugus, in southern New Hampshire. Ecology 58:775786. doi: $10.2307 / 1936213$

Anthony ELP, Stack MH, Kunz TH (1981) Night roosting and the nocturnal time budget of the little brown bat, Myotis lucifugus: effects of reproductive status, prey density, and environmental conditions. Springer-Verlag

Audet D (1990) Foraging behavior and habitat use by a gleaning bat Myotis myotis (Chiroptera: Vespertilionidae). J Mammal 71:420-427

Audet D, Fenton MB (1988) Heterothermy and the use of torpor by the bat Eptesicus fuscus (Chiroptera, Vespertilionidae) a field study. Physiol Zool 61:197-204

Bale JS et al (2002) Herbivory in global climate change research: direct effects of rising temperature on insect herbivores. Glob Chang Biol 8:1-16. doi:10.1046/j.1365-2486.2002.00451.x
Barclay RMR (1989) The effect of reproductive condition on the foraging behavior of female hoary bats, Lasiurus cinereus. Behav Ecol Sociobiol 24:31-37

Barclay RMR (1991) Population structure of temperate zone insectivorous bats in relation to foraging behavior and energy demand. $\mathrm{J}$ Anim Ecol 60:165-178. doi:10.2307/5452

Barclay RMR, Jacobs DS (2011) Differences in the foraging behaviour of male and female Egyptian fruit bats (Rousettus aegyptiacus). Can J Zool 89:466-473. doi:10.1139/z11-013

Bartoń K (2015) MuMIn: multi-model inference ( $\mathrm{R}$ package version 1.15.1). Available at: http://CRANR-projectorg/package = MuMIn

Beck A (1995) Fecal analyses of European bat species. Myotis 32-33: 109-119

Bell GP, Bartholomew GA, Nagy KA (1986) The roles of energetics, water economy, foraging behavior, and geothermal refugia in the distribution of the bat, Macrotus californicus. J Comp Physiol B 156:441-450. doi:10.1007/bf01101107

Bergeson SM, Carter TC, Whitby MD (2013) Partitioning of foraging resources between sympatric Indiana and little brown bats. J Mammal 94:1311-1320. doi:10.1644/12-mamm-a-311

Bernadzki E, Bolibok L, Brzeziecki B, Zajaczkowski J, Zybura H (1998) Compositional dynamics of natural forests in the Bialowieża National Park, northeastern Poland. J Veg Sci 9:229-238. doi: $10.2307 / 3237122$

Bihari Z (2004) The roost preference of Nyctalus noctula (Chiroptera, Vespertilionidae) in summer and the ecological background of their urbanization. Mammalia 68:329-336

Bogdanowicz W, Ruprecht AL (2004) Nyctalus leisleriKleinabendsegler. In: Krapp F (ed) Handbuch der Säugetiere Europas vol 4/II. AULA-Verlag, Wiebelsheim, pp. 717-756

Brigham RM, Fenton MB (1991) Convergence in foraging strategies by two morphologically and phylogenetically distinct nocturnal aerial insectivores. J Zool 223:475-489

Catto CMC, Racey PA, Stephenson PJ (1995) Activity patterns of the serotine bat (Eptesicus serotinus) at a roost in Southern England. J Zool 235:635-644

Chruszcz BJ, Barclay RMR (2003) Prolonged foraging bouts of a solitary gleaning/hawking bat, Myotis evotis. Can J Zool 81:823-826. doi:10.1139/z03-056

Clare EL, Barber BR, Sweeney BW, Hebert PDN, Fenton MB (2011) Eating local: influences of habitat on the diet of little brown bats (Myotis lucifugus). Mol Ecol 20:1772-1780. doi:10.1111/j.1365294X.2011.05040.x

Clare EL et al (2014) The diet of Myotis lucifugus across Canada: assessing foraging quality and diet variability. Mol Ecol 23:36183632. doi: $10.1111 / \mathrm{mec} .12542$

Core Team R (2015) R: a language and environment for statistical computing. R Foundation for Statistical Computing, Vienna

Dechmann DKN, Heucke SL, Giuggioli L, Safi K, Voigt CC, Wikelski M (2009) Experimental evidence for group hunting via eavesdropping in echolocating bats. Proc Biol Sci 276:2721-2728. doi:10.1098 /rspb.2009.0473

Dietz C, Nill D, Helversen OV (2009) Bats of Britain, Europe and Northwest Africa. A \& C Black, London

Dietz M, Kalko EKV (2006) Seasonal changes in daily torpor patterns of free-ranging female and male Daubenton's bats (Myotis daubentonii). J Comp Physiol B 176:223-231. doi:10.1007 /s00360-005-0043-x

Dietz M, Kalko EKV (2007) Reproduction affects flight activity in female and male Daubenton's bats, Myotis daubentonii. Can J Zool 85: 653-664. doi:10.1139/z07-045

Duverge PL, Jones G, Rydell J, Ransome RD (2000) Functional significance of emergence timing in bats. Ecography 23:32-40

Dzal YA, Brigham RM (2013) The tradeoff between torpor use and reproduction in little brown bats (Myotis lucifugus). J Comp Physiol B 183:279-288. doi:10.1007/s00360-012-0705-4 
Encarnação JA (2012) Spatiotemporal pattern of local sexual segregation in a tree-dwelling temperate bat Myotis daubentonii. J Ethol 30:271278. doi:10.1007/s10164-011-0323-8

Faliński JB (1986) Vegetation dynamics in temperate lowland primeval forests: ecological studies in Białowieża forest. Dr. W. Junk Publishers, Dodrecht

Frick WF, Stepanian PM, Kelly JF, Howard KW, Kuster CM, Kunz TH, Chilson PB (2012) Climate and weather impact timing of emergence of bats. PLoS One 7. doi:10.1371/journal.pone.0042737

Gebhard J, Bogdanowicz W (2004) Nyctalus noctula-Großer Abendsegler. In: Krapp F (ed) Handbuch der Säugetiere Europas vol 4/II. AULA-Verlag, Wiebelsheim, pp. 607-694

Gelman A, Su Y-S (2015) Data analysis using regression and multilevel/ hierarchical models (R package version 1.8-6). Available at: http://CRANR-projectorg/package $=$ arm

Gloor S, Stutz H-PB, Ziswiler Z (1995) Nutritional habits of the noctule bat Nyctalus noctula Schreber (1774) in Switzerland. Myotis 32-33: 231-242

Grueber CE, Nakagawa S, Laws RJ, Jamieson IG (2011) Multimodel inference in ecology and evolution: challenges and solutions. J Evol Biol 24:699-711. doi:10.1111/j.1420-9101.2010.02210.x

Horàcek I, Hanák V, Gaisler J (2000) Bats of the Palearctic region: a taxonomic and biogeographic review. Proceedings of the VIIIth EBRS Vol 1 Approaches to biogeography and ecology of bats:11157

Jones G (1995) Flight performance, echolocation and foraging behavior in noctule bats Nyctalus noctula. J Zool 237:303-312

Kan̆uch P (2007) Evening and morning activity schedules of the noctule bat (Nyctalus noctula) in Western Carpathians. Mammalia 71:126130. doi:10.1515/mamm.2007.026

Kaňuch P, Kristin A, Kristofik J (2005) Phenology, diet, and ectoparasites of Leisler's bat (Nyctalus leisleri) in the Western Carpathians (Slovakia). Acta Chiropterol 7:249-257. doi:10.3161/1733-5329 (2005)7[249:pdaeol]2.0.co;2

Kaňuch P, Ruczyński I, Cel'uch M (2004) Unusual change of habitat by a noctule female (Nyctalus noctula). Nyctalus 9:504-506

Kowalski K, Ruprecht AL (1981) Order: bats - Chiroptera. In: Pucek Z (ed) Keys to vertebrates of Poland. Mammals. Polish Scientific Publishers, Warszawa, pp. 101-154

Kronfeld-Schor N, Dayan T (2003) Partitioning of time as an ecological resource. Annu Rev Ecol Systemat 34:153-181. doi:10.1146 /annurev.ecolsys.34.011802.132435

Kronwitter F (1988) Population structure, habitat use and activity patterns of the noctule bats Nyctalus noctula Schreb. 1774 (Chirpotera, Vespertilionidae) revealed by radio-tracking. Myotis 26:23-85

Król E, Speakman JR (2003) Limits to sustained energy intake VI. Energetics of lactation in laboratory mice at thermoneutrality. J Exp Biol 206:4255-4266. doi:10.1242/jeb.00674

Kunz TH (1973) Resource utilization-temporal and spatial components of bat activity in Central Iowa. J Mammal 54:14-32. doi:10.2307 $/ 1378869$

Kunz TH (1974) Feeding ecology of a temperate insectivorous bat (Myotis velifer). Ecology 55:693-711. doi:10.2307/1934408

Kurta A, Kunz TH, Nagy KA (1990) Energetics and water flux of freeranging big brown bats (Eptesicus fuscus) during pregnancy and lactation. J Mammal 71:59-65

Mackenzie GA, Oxford GS (1995) Prey of the noctule bat (Nyctalus noctula) in East Yorkshire. J Zool 236:322-327

Maier C (1992) Activity patterns of pipistrelle bats (Pipistrellus pipistrellus) in Oxfordshire. J Zool 228:69-80

Muijres FT, Johansson LC, Bowlin MS, Winter Y, Hedenstroem A (2012) Comparing aerodynamic efficiency in birds and bats suggests better flight performance in birds. PLoS One 7. doi:10.1371/journal. pone. 0037335
Murray SW, Kurta A (2004) Nocturnal activity of the endangered Indiana bat (Myotis sodalis). J Zool 262:197-206. doi:10.1017 /s0952836903004503

Nad'o L, Kaňuch P (2015) Swarming behaviour associated with group cohesion in tree-dwelling bats. Behav Process 120:80-86. doi:10.1016/j.beproc.2015.09.005

Nardone V et al (2015) How to be a male at different elevations: ecology of intra-sexual segregation in the trawling bat Myotis daubentonii. PLoS One 10:e0134573. doi:10.1371/journal.pone.0134573

Neuweiler G (2000) The biology of bats. Oxford University Press, New York Oxford

Norberg UM, Rayner JMV (1987) Ecological morphology and flight in bats (Mammalia, Chiroptera): wing andaptations, flight performance, foraging strategy and echolocation. Philos Trans R Soc Lond Ser B Biol Sci 316:335-427

Olszewski JL (1986) Rola ekosystemów leśnych w modyfikacji klimatu lokalnego Puszczy Białowieskiej. Prace habilitacyjne. Wydawnictwo PAN Ossolineum, Wrocław

Polakowski M, Broniszewska M, Ruczyński I (2014) Local concentration of foraging noctule bats (Nyctalus noctula) as a possible tool to assess the density of bats in large forest complexes. Turk J Zool 38:254-256. doi:10.3906/zoo-1304-15

Racey PA, Speakman JR, Swift SM (1987) Reproductive adaptations of heterothermic bats at the northern borders of their distribution. S Afr J Sci 83:635-638

Racey PA, Swift SM (1985) Feeding ecology of Pipistrellus pipistrellus (Chiroptera, Vespertilionidae) during pregnancy and lactation. 1. Foraging behavior. J Anim Ecol 54:205-215. doi: 10.2307/4631

Rachwald A (1992) Habitat preference and activity of the noctule bat Nyctalus noctula in the Bialowieza Primeval Forest. Acta Theriol 37:413-422

Rachwald A, Ruczyński I (2015) Common pipistrelle (Pipistrellus pipistrellus Schreber, 1774) in the bat fauna of the Bialowieza Primeval Forest. Leśne Prace Badawcze 76:180-183

Rintoul JLP, Brigham RM (2014) The influence of reproductive condition and concurrent environmental factors on torpor and foraging patterns in female big brown bats (Eptesicus fuscus). J Comp Physiol B 184:777-787. doi:10.1007/s00360-014-0837-9

Ruczyński I (2006a) Influence of temperature on maternity roost selection by noctule bats (Nyctalus noctula) and Leisler's bats ( $N$ leisleri) in Białowieża Primeval Forest, Poland. Can J Zool 84:900-907. doi: 10.1139/z06-060

Ruczyński I (2006b) Influence of temperature on maternity roost selection by noctule bats (Nyctalus noctula) and Leisler's bats ( $N$ leisleri) in Białowieża Primeval Forest, Poland. Can J Zool 84:900-907. doi: 10.1139/z06-060

Ruczyński I, Bartoń KA (2012) Modelling sensory limitation: the role of tree selection, memory and information transfer in bats' roost searching strategies. PLoS One 7. doi:10.1371/journal. pone. 0044897

Ruczyński I, Bogdanowicz W (2005) Roost cavity selection by Nyctalus noctula and $N$ leisleri (Vespertilionidae, Chiroptera) in Białowieza Primeval Forest, eastern Poland. J Mammal 86:921-930. doi:10.1644/1545-1542(2005)86[921:rcsbnn]2.0.co;2

Ruczyński I, Bogdanowicz W (2008) Summer roost selection by treedwelling bats Nyctalus noctula and N leisleri: a multiscale analysis. J Mammal 89:942-951. doi:10.1644/07-mamm-a-134.1

Ruczyński I, Kalko EKV, Siemers BM (2007) The sensory basis of roost finding in a forest bat, Nyctalus noctula. J Exp Biol 210:3607-3615. doi:10.1242/jeb.009837

Ruczyński I, Ruczyńska I (2000) Roosting sites of Leisler's bat Nyctalus leisleri in Białowieża Forest-preliminary results. Myotis 37:55-60

Ruczyński I, Ruczyńska I (2008) Pond bat Myotis dasycneme as a new mammal species in Białowieża Primeval Forest. Nietoperze 9:79-80

Rydell J (1993) Variation in foraging activity of an aerial insectivorous bat during reproduction. J Mammal 74:503-509. doi:10.2307/1382411 
Rydell J, Entwistle A, Racey PA (1996) Timing of foraging flights of three species of bats in relation to insect activity and predation risk. Oikos 76:243-252. doi:10.2307/3546196

Sachanowicz K, Ciechanowski M (2005) Nietoperze Polski. Multico, Warszawa

Safi K (2008) Social bats: the males' perspective. J Mammal 89:13421350. doi: $10.1644 / 08-m a m m-s-058.1$

Senior P, Butlin RK, Altringham JD (2005) Sex and segregation in temperate bats. Proc Biol Sci 272:2467-2473. doi:10.1098/rspb.2005.3237

Shiel CB, Duverge PL, Smiddy P, Fairley JS (1998) Analysis of the diet of Leisler's bat (Nyctalus leisleri) in Ireland with some comparative analyses from England and Germany. J Zool 246:417-425. doi:10.1111/j.1469-7998.1998.tb00173.x

Shiel CB, Fairley JS (1999) Evening emergence of two nursery colonies of Leisler's bat (Nyctalus leisleri) in Ireland. J Zool 247:439-447. doi:10.1017/s0952836999004033

Shiel CB, Fairley JS (2000) Observations at two nursery roosts of Leisler's bats Nyctalus leisleri (Kuhl, 1817) in Ireland. Myotis 37: $41-53$

Shiel CB, Shiel RE, Fairley JS (1999) Seasonal changes in the foraging behaviour of Leisler's bats (Nyctalus leisleri) in Ireland as revealed by radio-telemetry. J Zool 249:347-358. doi:10.1111/j.14697998.1999.tb00770.x

Siemers BM, Schnitzler HU (2004) Echolocation signals reflect niche differentiation in five sympatric congeneric bat species. Nature 429:657-661. doi:10.1038/nature02547

Speakman JR (1991) Why do insectivorous bats in Britain not fly in daylight more frequently? Funct Ecol 5:518-524. doi:10.2307 $/ 2389634$
Speakman JR (1995) Chiropteran nocturnality ecology, evolution and behaviour of bats:187-201

Speakman JR, Thomas DW (2003) Physiological ecology and energetics of bats. In: Kunz TH, Fenton MB (eds) Bat ecology. The University of Chicago Press, Chicago and London, pp. 430-490

Studier EH, Ofarrell MJ (1972) Biology of Myotis thysanodes and M lucifugus (Chiroptera Vespertilionidae 1. Thermoregulation). Comp Biochem Physiol 41:567-\&amp. doi:10.1016/0300-9629(72 )90014-x

Symes CT, Wilson JW, Woodborne SM, Shaikh ZS, Scantlebury M (2013) Resource partitioning of sympatric small mammals in an African forest-grassland vegetation mosaic. Austral Ecol 38:721729. doi:10.1111/aec. 12020

Taylor LR (1963) Analysis of the effect of temperature on insects in flight. J Anim Ecol 32:91-117

Voigt CC, Soergel K, Dechmann DKN (2010) Refueling while flying: foraging bats combust food rapidly and directly to power flight. Ecology 91:2908-2917. doi:10.1890/09-2232.1

Vonhof MJ, Betts BJ (2010) Nocturnal activity patterns of lactating silverhaired bats (Lasionycteris noctivagans): the influence of roostswitching behavior. Acta Chiropterol 12:283-291. doi:10.3161 /150811010x537864

Wesołowski T (2007) Lessons from long-term hole-nester studies in a primeval temperate forest. J Ornithol 148:S395-S405. doi:10.1007 /s10336-007-0198-1

Wolbert SJ, Zenner AS, Whidden HP (2014) Bat activity, insect biomass, and temperature along an elevational gradient. Northeast Nat 21:7285. doi:10.1656/045.021.0106 